\title{
CURRENT COVID-19 IMPACT ON SAUDI STOCK MARKET: EVIDENCE FROM AN ARDL MODEL
}

\author{
Chaouachi Maroua (PhD in Finance) \\ High Institute of Management/University of Tunis/Tunisia. \\ Chaouachi Slim (Assistant professor in Economics) \\ High Institute of Management/University of Tunis/Tunisia.
}

Correspondence address:

Disclosure statement:

Conflict of interest:

Cite this article:
High Institute of Management Street of Liberty, Bouchoucha University of Tunis

Tunisia

2000

0021655603823

Authors are not aware of any findings that might be perceived as affecting the objectivity of this study.

The author reports no conflict interest

Chaouachi, M. \& Chaouachi, S. (2020). Current COVID-19 impact on Saudi Stock Market: Evidence from an ARDL Model. International Journal of Accounting, Finance, Auditing, Management \& Economics, pp. 1-13.

DOI: 


\title{
CURRENT COVID-19 IMPACT ON SAUDI STOCK MARKET: EVIDENCE FROM AN ARDL MODEL
}

\begin{abstract}
This paper investigates the effect of COVID-19 pandemic on stock market in KSA applying an Autoregressive Distributed Lag (ARDL) cointegration approach. More especially, we analyze the relationship between the natural logarithm of trading volume of Tadawull All shares index (TASI) and the natural logarithm of daily COVID-19 confirmed cases both in the short-run and the long-run. The bounds test for cointegration is carried out for daily series over the period from March 02, 2020 till May 20, 2020.Toda-Yamamoto causality test is implemented between variables. Our findings indicate that there is a negative impact of COVID-19 on stock market only in the long-run. Causality test reveals a unidirectional causality from COVID-19 prevalence's measure to stock market. Robustness check seems to be conclusive.
\end{abstract}

Keywords: Stock Market, COVID-19, ARDL, Bounds test, KSA.

JEL Classification: I10, G15, C32, O53

Paper type: Empirical research

Published online: 10 July 2020 


\section{Introduction}

The world has tried to compact, since the beginning of the century, the widespread of many pandemics and epidemics-prone diseases including the severe acute respiratory syndrome (SARS) in 2003, the $2009 \mathrm{H} 1 \mathrm{~N} 1$ influenza pandemic, the 2012 Middle East respiratory syndrome (MERS), the 2014 epidemic of Ebola (Abdulazeez, 2020). For a long time, costs and repercussions of these diseases have been enormous to human health, to economies, and even to national security (Qiu and al. 2017). At the end of December 2019, a novel Coronavirus (COVID-19) disease appeared in Wuhan, China (Brüssow, 2020; Fauci, Lane \& Redfield, 2020; Gentile \& Abenavoli, 2020; Shang, Yang, Rao \& Rao, 2020). On March 11, 2020, the World Health Organization (WHO) announced COVID-19 outbreak a global pandemic. Thus, it is an important wake-up call for all countries because it poses also a serious threat to public health and overall economy on both national and international level. According to Evans (2020), he confirms that COVID-19's economic effects are not merely considerable but positively harmful inasmuch as they caused permanent markets closure, long-term job losses amidst this pandemic, etc. Likewise, the current Coronavirus has wide-ranging and noteworthy shock waves on financial market that is made up of debt, commodity (crude oil and gold) and stock markets.

In this regard, this study illustrates with the impact of the COVID-19 on stock market in KSA. We attempt to examine how the natural logarithm of daily COVID-19 confirmed cases affects the natural logarithm of trading volume of Tadawull All shares index (TASI) in KSA by introducing an Autoregressive Distributed Lag (ARDL) cointegration technique in case of mixed level series I(0) or I(1). This approach allows seeing if the linkage between the two variables tends to change in a direction that brings it closer to its long-run equilibrium.

The remainder of the paper proceeds as follows: The next section covers the literature review and hypotheses development. The section 3 focuses on methodology. Results are being discussed in the section 4 with robustness analysis. Finally, the section 5 draws the summary and conclusions of our research.

\section{Literature review and hypotheses development}

This section provides a review of existing empirical evidence concerning the link between financial market and Coranavirus pandemic. This literature provides the basis for subheading 2.2 in which we develop hypotheses of our investigation.

\subsection{Background}

Within the first line of study looking to the to the impact of Covid-19 on stock market, Qing He and al., (2020) use conventional t-tests and nonparametric Mann-Whitney tests to analyze the direct and spill-over effects of COVID-19 on daily stock markets returns in China, Italy, South Korea, France, Spain, Germany, Japan and the USA over the period June 01, 2019 till March 22, 2020. They find that COVID-19 has a negative but short-term effect on stock markets returns in these countries. Also, they note that the spill-over effects of COVID-19 on stock markets is bidirectional between Asian countries and European and American countries. However, they report that there is no evidence this pandemic exert negative on stock markets of these states more than it does the global average. 
More recently, Al-Awadhi and al., (2020) investigate the effect of the COVID-19 pandemic on Chinese stock market. The analysis extends from $10^{\text {th }}$ January, 2020 to $16^{\text {th }}$ March, 2020, through the method of panel data. Daily stock returns represent the endogenous variable. Prevalence of COVID-19 was measured with (1) daily growth in total confirmed cases and (2) daily growth in total deaths caused by COVID-19. These two indicators are mixed with a number of control variables: (1) the natural logarithm of daily market capitalization and daily market-to-book ratio. Results of their estimation show that the decrease in both the daily growth in total confirmed cases and in total cases of death caused by COVID-19 involves the increase on stock returns across all companies. Also, they prove that control variables are negative and significant. Authors perform several robustness analyses with firm fixed-effects and cluster robust estimators by firm and they find same results.

In the same spirit, Ben Ayed and al., (2020) employ the Swamy-Arora method for panel data analysis to examine the reaction of Tunisian stock market to current COVID-19 pandemic. Data starts from January 20 and ends at April 20, 2020 with an indicator of stock market presented by the stock returns performance of all companies listed on the Tunis Stock Exchange. The COVID-19 is measured by (1) the daily growth of confirmed cases (2) the daily growth of death tolls and (3) the daily growth of recovered cases. They conclude that daily growth of confirmed cases has a positive relationship with stock returns, while daily growth of deaths cases affect negatively the performance of stock returns. Conversely, daily growth of recovered cases has a positive impact but not significant. At the same time, they support that Tunisians authorities have an important role in wrestling the spillover of the pandemic by putting early preventive measures in order to protect population and save economy.

Using daily change in major stock index and daily growth in COVID-19 confirmed cases and mortalities data from 64 countries, on a daily basis from 22 January 2020 to 17 April 2020, a panel pooled ordinary least squares regression of Badar Nadeem Ashraf (2020) confirms that stock markets respond negatively to the increase in COVID-19 confirmed cases. He further documents a weak response of stock market to the growth in number of mortalities due to the COVID-19. Author adds a two-step further check. The first one with panel random-effects regression method and he obtains same results. The second step, he replaces country-level control variables and includes country fixed-effects dummy variables to verify if results are not driven by omitted variables in a cross-country setting. Results are the same as those obtained by the panel pooled ordinary least squares regression and confirm that are not biased. Overall, he concludes that the response of stock markets to COVID-19 pandemic is quick and its variation over time depends on the severity of outbreak.

Sansa (2020) evaluates the relationship between the COVID-19 confirmed cases and all the financial markets in USA and China (New York Dow Jones and Shanghai stock exchange). Their study covers the period from $1^{\text {st }}$ March 2020 to $25^{\text {th }}$ March 2020. According to results, he discovers that COVID-19 confirmed cases affect positively and significantly the financial markets in these countries. That means the COVID-19 had a significant impact on the financial markets during this period.

In a study carried out in the worst 6 countries (according to the daily number of cumulative cases of COVID-19, they represented $67.6 \%$ of worldwide cases as of $10^{\text {th }}$ April, 2020) from $1^{\text {st }}$ March 1, 2020 to $10^{\text {th }}$ April, 2020, Alber (2020) investigates how the Coronavirus spread affected stock markets using numbers per million of population as a measure of Coronavirus spread, while $\Delta$ in stock market index as a measure of stock market return. The author resorts to the GMM technique and documents a sensitivity of stock market to Coronavirus cases more 
than mortalities, and to Coronavirus cumulative indicators more than new ones. Besides, robustness analysis using OLS regression provides evidence of a significant negative impact of Coronavirus spread on stock market return for China, Germany, France and Spain but not for American and Italian markets.

HaiYue Liu and al.,(2020) document a short-term impact of the Coronavirus outbreak on 21 leading stock market indices in the most affected countries by virus including Japan, Korea, Singapore, USA, Germany, Italy, UK etc. In fact, they notice that COVID-19 confirmed cases reduce stock market indices daily abnormal returns after the outbreak by using OLS regression. This negative interaction is greater in Asian markets than others markets. Moreover, this study investigates investor's fear sentiment triggered by COVID-19 on stock markets. This sentiment proved to be a complete mediator and transmission channel for the COVID-19 outbreak's effect on stock markets. As robustness check, they use FGLS estimation with heteroscedastic residues terms including time dummies and confirm also this negative significance.

Additionally, Elsayed and al., (2020) examine the effects of COVID-19 spread on 17 sectors of stock exchange of Egypt over the period from March 1, 2020 till May 10, 2020. The dependent variable is measured by the returns of the daily sectoral indicators for the Egyptian stock market. COVID-19 measurements are constituted by cumulative cases, new cases, cumulative deaths, and new deaths. They find that stock market's returns of all sectors seem to be more sensitive to cumulative death indicators than daily mortalities caused by COVID-19, and new cases more than COVID-19's cumulative cases.

An extensive literature survey by Goodell (2020), emphasizing the economic effects of natural disasters, such as nuclear wars, climate change or localized disasters, proves that COVID-19 pandemic has caused more serious financial distractions (including stock markets, banking and insurance) than those are caused by previous disasters. Likewise, Zhang et al., (2020) prove that COVID-19 increases financial markets risks.

Recent analysis conducted by El-Basuony (2020) reveals that there is a negative significant relationship between the confirmed cases and death cases from COVID-19 and the volume trading on stock exchange in KSA and Egypt over the period April 01, 2020 till May 21, 2020. Applying an OLS regression, empirical results show that COVID-19 has a significant impact on the financial markets in these two countries.

Gormsen and Koijen (2020) tries to quantify how American and European investors' expectations about economic growth across horizons evolve in response to the Coronavirus outbreak and subsequent policy responses by using data from the aggregate equity market and dividend futures.

Summarizing, the existing literature regarding the link between financial market and COVID19 is quite limited. Thus, the current study contributes to the literature in 3 important ways:

a) It contributes to the recently emerging evidence investigating the effect of more recent pandemic COVID-19 on Arab financial markets, which remains also limited.

b) This study examines Arab stock market in KSA in the period from $2^{\text {nd }}$ March 2020 to $21^{\text {th }}$ May 2020. Our study is made upon detection of the first case of COVID-19 in Saudi Arabia. 
c) As far as we know, this is the first research looking to both the long-run dynamics and the short-run relationship between stock market in KSA and COVID-19 spillover using ARDL specification.

d) It contributes to the existing literature on financial market and COVID-19 by providing additional insights into the direction of the causality by using the Toda-Yamamoto causality test.

\subsection{Hypotheses development}

The antecedent subsection discussed current literature with regard to effects of COVID-19 on financial markets. It forms the basis for the hypotheses of my paper:

H1: "There exists a significant relationship between COVID-19 and Saudi stock market in the short-run."

H2: "There exists a significant relationship between COVID-19 and Saudi stock market in the long-run.

\section{Methodology}

In order to study the impact of COVID-19 the KSA stock market, we estimate an Autoregressive Distributed Lag (ARDL) model. This technique developed by Pesaran and Shin (1999) and Pearsan and al., (2001) is an alternative to test cointegration of Engel and Granger (1987) and Johansen $(1988,1991)$. It allows, on the one hand, to test the long term-run using a set of variables which are not integrated of the same order I (0) or (1) (Senay and Merter, 2010). On the second hand, by applying the ARDL approach we get unbiased estimates of the longrun relationship (Harris and Sollis, 2003) and finally it is better suited to small samples (Narayan, 2005).The optimum number of lags of the dependent variable and the interest variable is selected based on the Akaike Information Criteria (AIC). We also try to test the existence of a causal relation between these two variables.

\subsection{Research model}

The answers to the hypotheses below are estimated by the ARDL approach. Thus, our ARDL model is given by the following equation:

$$
\begin{aligned}
& \Delta \mathrm{LOG}_{-} \mathrm{TASI}_{(\mathrm{t})}=\mathrm{C}+\sum_{\mathrm{i}=1}^{\mathrm{p}} \alpha_{1 \mathrm{i}} \Delta \mathrm{LOG} \_\mathrm{TASI}_{(\mathrm{t}-\mathrm{i})}+\sum_{\mathrm{i}=0}^{\mathrm{q}} \alpha_{2 \mathrm{i}} \Delta \mathrm{LOGCOVID}{ }_{-} 19_{(\mathrm{t}-\mathrm{i})}+\beta_{1} \mathrm{LOG}_{-} \mathrm{TASI}_{(\mathrm{t}-\mathrm{l})}+ \\
& \beta_{2} \mathrm{LOGCOVID}_{-}{ }^{19_{(\mathrm{t}-1)}}+\varepsilon_{(\mathrm{t})}
\end{aligned}
$$

In eq.(1), TASI is the trading volume of Tadawull All shares index; COVID-19 is the daily number of confirmed cases COVID-19; C is the constant; LOG (.) is the natural logarithm operator; $\Delta$ is the first difference operator; $\alpha_{1}$ and $\alpha_{2}$ are the short-run coefficients; $\beta_{1}$ and $\beta_{2}$ are the long-run dynamics; $\varepsilon_{(\mathrm{t})}$ is the error term.

To study the existence of long-run dynamics between variables, we calculate the "Bounds test to cointegration" based on Fisher statistic on hypothesis: 
$H_{0}: \beta_{1}=\beta_{2}=0$. The reject of $H_{0}$ implies the presence of cointegration. $H_{0}$ is rejected when the Fstatistic exceeds the upper bounds value I(1), while it is accepted if the F-statistic is lower than the lower critical bounds value I( 0$)$. If not, we can't conclude.

In presence of cointegration, the long-run relationship is obtained by cancellation of variables in the first difference (Morley, 2006 and Antoniou and al., 2013). On the basis of eq.(1), we deduce that it is represented by the following equation:

$\mathrm{LOG}_{-} \mathrm{TASI}_{(\mathrm{t})}=-\left(\frac{\mathrm{C}}{\beta_{1}}\right)-\left(\frac{\beta_{2}}{\beta_{1}}\right) \operatorname{LOGCOVID~}_{-}{ }^{19}(\mathrm{t})$

An Error Correction Model (ECM) for eq.2 can help to confirm the existence or not of cointegration between variables as following:

$$
\begin{aligned}
& \Delta \mathrm{LOG}_{-} \operatorname{TASI}_{(\mathrm{t})}=\sum_{\mathrm{i}=1}^{\mathrm{p}} \alpha_{1 \mathrm{i}} \Delta \mathrm{LOG}_{-} \mathrm{TASI}_{(\mathrm{t}-\mathrm{i})}+\sum_{\mathrm{i}=0}^{\mathrm{q}} \alpha_{2 \mathrm{i}} \Delta \mathrm{LOGCOVID}_{-} 19_{(\mathrm{t}-\mathrm{i})}+\beta_{1} \mathrm{ECM}_{(\mathrm{t}-1)}+\varepsilon_{\mathrm{t}}^{\prime} \\
& \mathrm{ECM}_{(\mathrm{t})}=\mathrm{LOG}_{-} \operatorname{TASI}_{(\mathrm{t})}-\left[-\left(\frac{\mathrm{C}}{\beta_{1}}\right)-\left(\frac{\beta_{2}}{\beta_{1}}\right) \operatorname{LOGCOVID}_{-} 19_{(\mathrm{t})}\right]
\end{aligned}
$$

\subsection{Data and description}

Trading volume of Tadawull All shares index (TASI) daily data are downloaded from the www.investing.com website. Additionally, the daily number of confirmed cases of the COVID19 is collected from the official website of Ministry of Health of KSA. Our sample coves the period started from 02 March 2020 to 20 May 2020. The starting day $02^{\text {nd }}$ March, 2020 has been chosen because as of this date the Saudi Arabia was detected the COVID-19's first case. Note that variables are transformed into the natural logarithm.

\section{Results and discussions}

In this section, we provide the empirical results and discussions. Subsection 4.1 presents the descriptive statistics of our variables. Subsection 4.2 continues with results of ARDL analysis of the key variable LOGCOVID_19 on the dependent variable LOG_TASI, concluded with some supplementary robustness check.

\subsection{Descriptive statistics}

Table 1 presents the descriptive statistics of all retained series. TASI denotes the trading volume of Stock market in KSA (TASI).COVID-19 denotes the daily confirmed cases of COVID-19 in KSA. 
Table1. Summary statistics of main variables ( $2^{\text {nd }}$ March 2020 to $20^{\text {th }}$ May 2020)

\begin{tabular}{lcc}
\hline Statistics & TASI & COVID-19 \\
\hline Mean & $1.45 \mathrm{e}+10$ & 1320.849 \\
Median & $4.84 \mathrm{e}+09$ & 1147 \\
Maximum & $2.74 \mathrm{e}+09$ & 4919 \\
Minimum & $2.74 \mathrm{e}+09$ & 0 \\
Std.div & $6.01 \mathrm{e}+10$ & 1351.407 \\
Skewness & 6.379362 & .9420209 \\
Kurtosis & 43.6263 & .9420209 \\
Observations & 73 & 73 \\
\hline \multicolumn{2}{l}{ Note: Outputs of data processing using } \\
\multicolumn{3}{l}{ STATA 12 } \\
\hline
\end{tabular}

Figure (1) highlights the movements of the trading volume of Tadawull All shares index (TASI) and COVID-19 daily confirmed cases starting with the first part of March.

Fig1. Movements of TASI and Covid_19 confirmed cases from 02/03/2020 to 20/05/2020

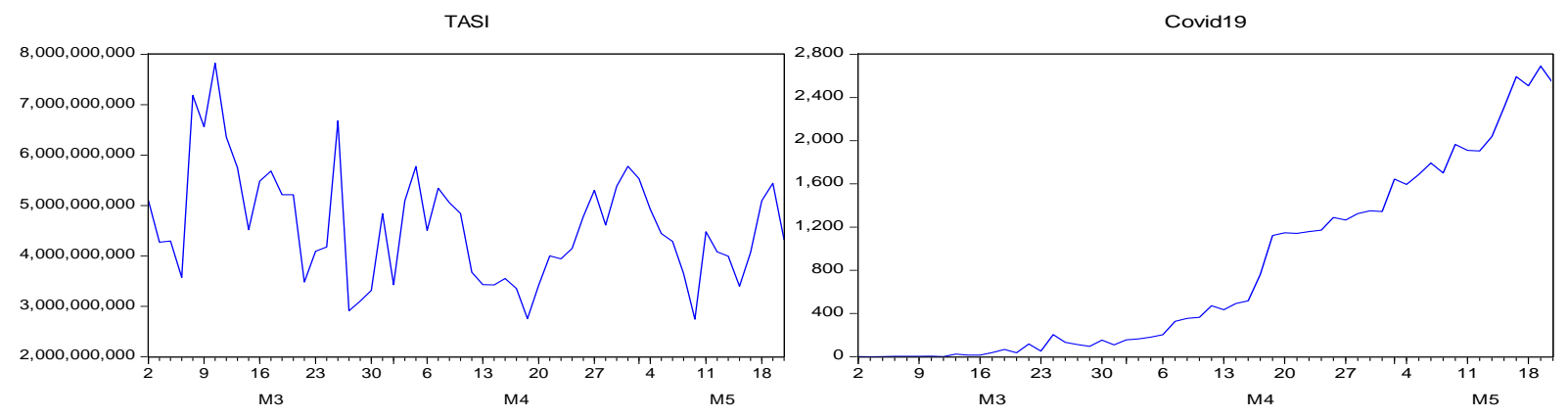

\subsection{Quantitative results and discussions}

\subsubsection{Unit Root tests}

Before proceeding to the ARDL approach, we test the stationary of all series. Results of Augmented Dickey-Fuller (ADF,1979) and Philips-Perron (PP, 1988) unit root tests, reported in Tables 2 and 3 indicate that all series are mixed either I (0) or I (1) and none of them is integrated of order 2 (I (2)). Hence the use of ARDL model is possible. LOG_TASI is stationary whereas LOGCOVID_19 presents a unit root. 
Table2. ADF Unit Root test on log level of variables

\begin{tabular}{llcllc}
\hline Variables & & t-statistic & \multicolumn{2}{c}{ Test critical values } & Integration order \\
\hline LOG_TASI & Level & $-4.1608(\mathrm{~b})^{* *}$ & $1 \%$ & -3.5504 & \\
& & $(0.0017)$ & $5 \%$ & -2.9135 & $\mathrm{I}(0)$ \\
& & & $10 \%$ & -2.5945 & \\
\cline { 2 - 6 } & First difference & $-10.6211(\mathrm{c})^{* * *}$ & $1 \%$ & -2.6069 & \\
& & $(0.0000)$ & $5 \%$ & -1.9467 & $\mathrm{I}(0)$ \\
\hline LOGCOVID_19 & Level & $-2.6785(\mathrm{~b})^{*}$ & $10 \%$ & -1.6131 & \\
& & $(0.0844)$ & $5 \%$ & -3.5575 & \\
& & & -2.9166 & $\mathrm{I}(1)$ \\
& First difference & $-14.1560(\mathrm{a})^{* * *}$ & $1 \%$ & -2.5961 & \\
& & $(0.0000)$ & $5 \%$ & -4.1373 & \\
& & & $10 \%$ & -3.4953 & $\mathrm{I}(0)$ \\
& & & $10 \%$ & \\
\hline
\end{tabular}

Note: $* * *, * * * *$ indicate the significance at the level $1 \%, 5 \%$ et $10 \%$. LOG_TASI is natural logarithm of the value of the trading volume of Tadawull All shares index, LOGCOVID_19 is the natural logarithm of the daily confirmed cases. We select 3 models: (a) model with intercept and trend (b) model without trend (c) model without intercept and trend. Optimal number of lags is based on AIC.

Table3. PP Unit Root test on log level of variables

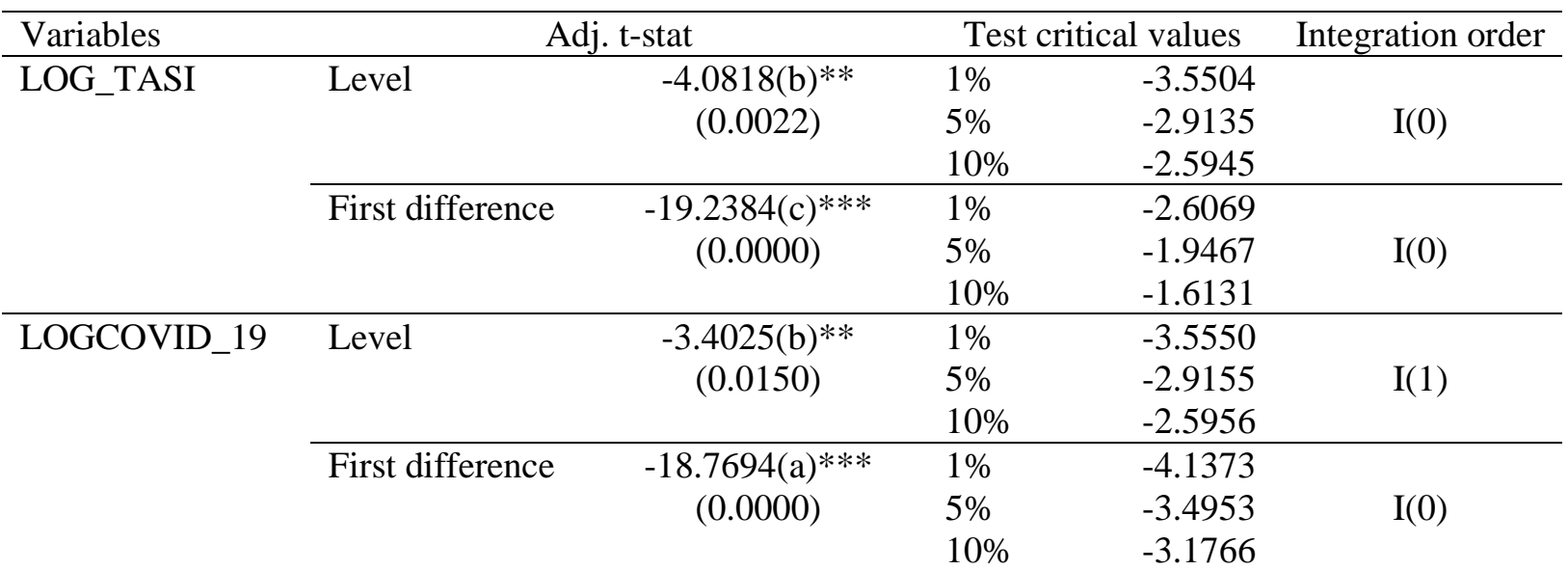

Note: $* * *, * * *$ indicate the significance at the level $1 \%, 5 \%$ et $10 \%$. LOG_TASI is natural logarithm of the value of the trading volume of Tadawull All shares index, LOGCOVID_19 is the natural logarithm of the daily confirmed cases. We select 3 models: (a) model with intercept and trend (b) model without trend (c) model without intercept and trend. Test critical values are those of Mackinnon (1996).

\subsubsection{ARDL estimation}

In order to select the optimal number of lag $(p, q)$ to the ARDL model, we used the Akaike Information Criterion (AIC).The ARDL (1,2) present the most optimal among 10. 
Fig2. Akaike information criteria

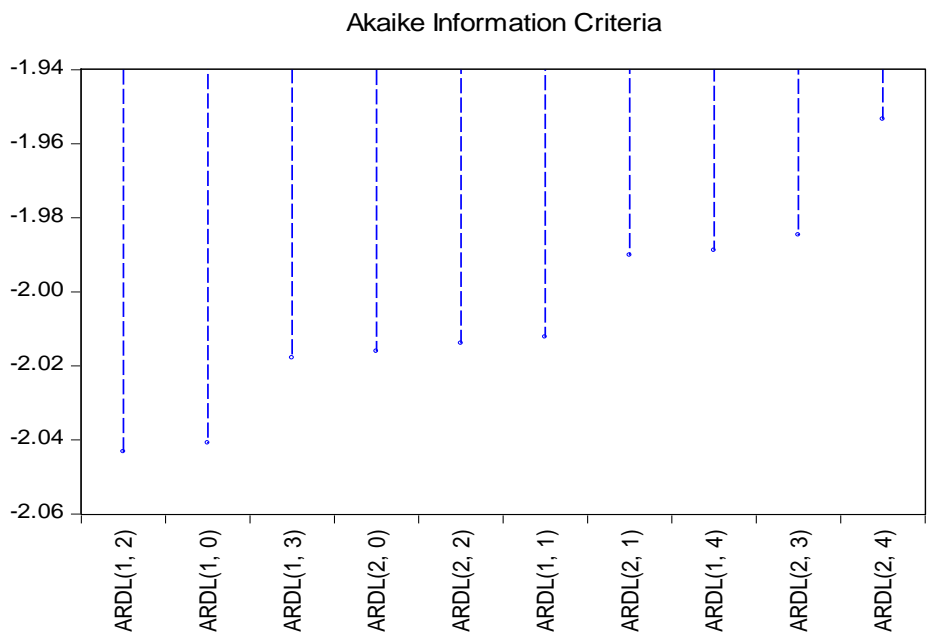

Table 4 shows that the major of coefficients of the ARDL model $(1,2)$ are significant (Prob $<5 \%$ ). Likewise, the model is globally significant, Prob (F-statistic) $=0.000016$ ). It should be noted that the model is estimated with the "constant" option, which is very significant (Prob < $1 \%)$.

Table4. ARDL $(1,2)$ estimation

\begin{tabular}{lcccc}
\hline Variable & Coefficient & Std. Error & t-Statistic & Prob.* \\
\hline LOG_TASI(-1) & 0.443533 & 0.120804 & 3.671522 & 0.0006 \\
LOGCOVID_19 & 0.011742 & 0.057716 & 0.203446 & 0.8396 \\
LOGCOVID_19(-1) & 0.077992 & 0.050849 & 1.533783 & 0.1315 \\
LOGCOVID_19(-2) & -0.119295 & 0.054456 & -2.190658 & 0.0333 \\
C & 5.435542 & 1.184644 & 4.588335 & 0.0000 \\
\hline F-statistic & 8.975826 & R-squared & & 0.422873 \\
Prob(F-statistic) & 0.000016 & & & \\
\hline
\end{tabular}

Despite the fact that the major of coefficients are significant and the model is also globally significant, however, it is important to check whether it is indeed valid. So we need to conduct validity tests, including autocorrelation tests of residues.

Table5. Autocorrelation of residuals

\begin{tabular}{|c|c|c|c|c|c|c|}
\hline Autocorrelation & Partial Correlation & & $\mathrm{AC}$ & PAC & Q-Stat & Prob* \\
\hline .1. & .1 & 1 & 0.050 & 0.050 & 0.1451 & 0.703 \\
\hline$* 1$. & * & 2 & -0.176 & -0.179 & 1.9504 & 0.377 \\
\hline$* 1$. & $*$ & 3 & -0.084 & -0.067 & 2.3713 & 0.499 \\
\hline$*$ &. & 4 & 0.120 & 0.101 & 3.2495 & 0.517 \\
\hline T. & . & 5 & 0.035 & -0.003 & 3.3257 & 0.650 \\
\hline . & .1. & 6 & -0.021 & 0.008 & 3.3534 & 0.763 \\
\hline$*$. &.$* 1$. & 7 & -0.146 & -0.130 & 4.7291 & 0.693 \\
\hline .1 & .1. & 8 & -0.005 & -0.002 & 4.7305 & 0.786 \\
\hline
\end{tabular}

Results of the Ljung-Box test indicate that the probability of the Q statistic is clearly greater than the 5\% and even 10\% threshold. Results strongly suggest the absence of autocorrelation in the model errors, which is essential to continue our estimation. Because if there is an 
autocorrelation of residues, parameters estimated will not be consistent, due to the presence of lagged dependent variable that appears as exogenous variable in the model.

Table6. Bound test to cointegation results

\begin{tabular}{llllll}
\hline Model & F-statistic & $\mathrm{k}$ & \multicolumn{2}{c}{ Critical value Bounds } & Conclusion \\
\cline { 4 - 4 } Specification & & & Lower bound I(0) & Upper bound I(1) & \\
ARDL(1,2) & $10.62920 * * *$ & 1 & $1 \%$ & $1 \%$ & Cointegration \\
& & 6.84 & 7.84 & \\
& & $5 \%$ & $5 \%$ & \\
& & 4.94 & 5.73 & \\
& & $10 \%$ & $10 \%$ & \\
& & 4.04 & 4.78 & \\
\hline \multicolumn{2}{l}{ Note: ***indicate the significance at the level 1\%. }
\end{tabular}

Bound test results confirmed the existence of cointegration relationship between series (F-stat $=10.62920>$ upper bound I (1)), which gives the possibility of estimating the long-run relationship between LOGCOVID_19 and LOG_TASI.

Table7. Dynamics of the short-run and long-run

\begin{tabular}{ccccc}
\hline \multicolumn{5}{c}{ Cointegrating Form } \\
\hline Variable & Coefficient & Std. Error & t-Statistic & Prob. \\
$\Delta$ (LOGCOVID_19) & 0.011742 & 0.057716 & 0.203446 & 0.8396 \\
$\Delta($ LOGCOVID_19(-1)) & 0.119295 & 0.054456 & 2.190658 & 0.0333 \\
ECM(-1) & -0.556467 & 0.120804 & -4.606380 & 0.0000 \\
\hline ECM(-1)= LOG_TASI $-(-0.0531 *$ LOGCOVID_19+9.7679) \\
\hline \multicolumn{5}{c}{ Long-Run Coefficients } \\
\hline Variable & Coefficient & Std. Error & t-Statistic & Prob. \\
LOGCOVID_19 & -0.053123 & 0.025200 & -2.108084 & 0.0402 \\
C & 9.767948 & 0.069033 & 141.496331 & 0.0000 \\
\hline
\end{tabular}

The long-run relationship is the following: LOG_TASI=9.7678***-0.0531* LOGCOVID_19. Results show that there is a negative significant long-term relationship between COVID_19 and stock market in KSA: an increase of the daily number of COVID-19 confirmed cases of 100\% led to a decrease of $5 \%$ of trading volume of Tadawull All shares index (TASI).

The term ECM (-1) corresponds to the lagged error from the long-term equilibrium equation. This coefficient expresses the degree to which the variable LOG_TASI will be recalled towards the long-term target. It is negative $(-0.5565)$ and largely significant (Prob $=0.0000<1 \%$ ), thus reflecting a relatively quick long-term target adjustment.

However, in the short-run relationship, it appears that there is no significance between all variables, but LOGCOVID_19 delayed by one day ( $\mathrm{t}-1$ ) has a positive and significant impact on LOG_TASI in day (t) at level 5\%. Despite of the coronavius pandemic, investors can implement some strategies increasing the number of transactions on the market: they can either buy stocks that have preserved gains despite the crisis and which should still perform well during and after COVID-19 (conservative approach) or/ and sell short-term stocks in difficulty that could still suffer from the pandemic if they think that it will continue. 
As we already know, correlation does not mean causality. To test the causality that can exist between variables, we are used the Toda Yamamoto causality test. As expected, a causality relationship ranging from LOGCOVID_19 to LOG_TASI is confirmed by Toda-Yamamoto causality test (Prob $=0.0043$, the null hypothesis is rejected). However, there is no causality from LOG_TASI to LOGCOVID_19 (Pob=0.4413).

Table8. Toda-Yamamoto causality test

\begin{tabular}{|c|c|c|c|c|}
\hline Dependant variable: LOG_TASI & Chi-sq & df & Prob. & Causality \\
\hline LOGCOVID_19 & 10.88628 & 2 & 0.0043 & LOGCOVID_19 $\Rightarrow$ LOG_TASI \\
\hline Dependant variable: LOGCOVID-19 & Chi-sq & $\mathrm{df}$ & Prob. & Causality \\
\hline LOG_TASI & 1.636264 & 2 & 0.4413 & LOG_TASI $\not \Rightarrow$ LOGCOVID_19 \\
\hline
\end{tabular}

\subsubsection{Robustness check}

We use some diagnostic tests of residuals for robustness analysis. It is about the test of BreuschGodfrey serial correlation LM autocorrelation Test of errors, the heteroskedasticity Test of Breusch-Pagan-Godfrey, Jarque Bera test for the Normality of residues and the stability test of CUSUM. All results confirm that there is no autocorrelation ( $\operatorname{Prob}=0.1715>5 \%$ ), no heteroskedasticity (Prob=0.939) and errors are normally distributed (Prob=0.4639).

Table9. Diagnostic tests results

\begin{tabular}{lcc}
\hline \multicolumn{1}{c}{ Test's hypothesis } & Tests & Values \\
\hline Autocorrelation & Breusch-Godfrey serial correlation LM & 1.831212 \\
& & $(0.1715)$ \\
Heteroskedasticity & Breusch-Pagan-Godfrey & 0.19 \\
& & $(0.9390)$ \\
Normality & Jarque Bera & 2.525339 \\
& & $(0.4639)$ \\
\hline Note: $* * *, * * *$ indicate the significance at level 10\%, 5\% and 1\%. & \\
\hline
\end{tabular}

Figure 3 illustrates the CUSUM test results and shows that all the parameters of the model are stables over time, because recursive errors remain, at the whole period, inside the confidence interval at level of $5 \%$.

Fig3. CUSUM stability test

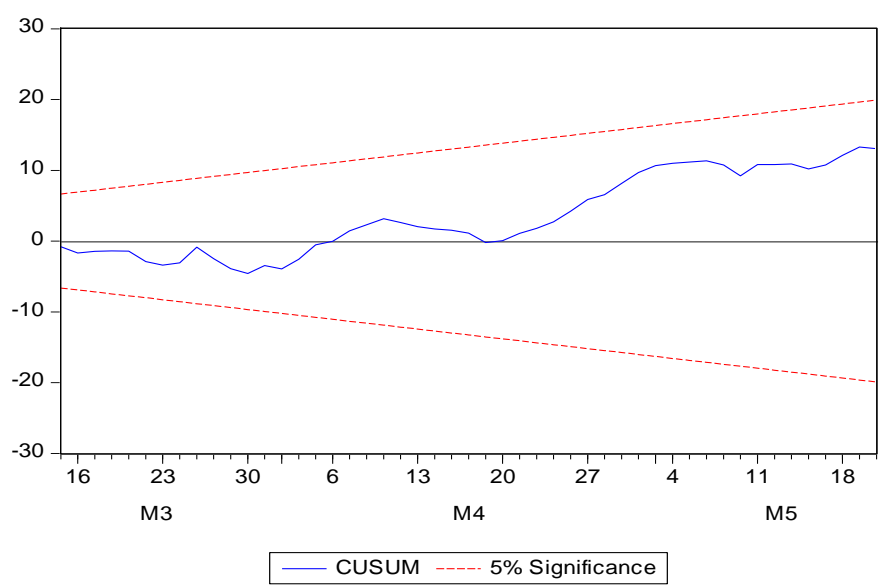




\section{Summary and conclusions}

The study focuses on modeling the effects of the Coronavirus spillover on stock market in KSA during the period from $2^{\text {nd }}$ March, 2020 to $20^{\text {th }}$ May, 2020 using an ARDL estimation approach. The natural logarithm is the trading volume of the KSA Stock Exchange (TASI) is the endogenous variable while LOGCOVID_19 daily confirmed case is the Corona prevalence's measure. Previous researches about effects of the COVID-19 epidemic on Arabic Stock Market remain limited, while this study is a contribution to this recently emerging literature. Moreover, it not only analyses the short-run relationship between Coronavirus and Saudi Stock Market, but also, the long-run and causality. Findings indicate (1) the presence of long-run negative relationship between LOG_TASI and LOGCOVID_19 (2) the causality between variables is unidirectional from LOGCOVID_19 to LOG_TASI. Robustness analysis confirms our results. Therefore, a powerful national response is needed, including tough measures to prevent a serious stock market crash in KSA in long-run.

\section{References}

(1) Abdulazeez, A.A. 2020. The coronavirus disease 2019 (COVID-19) pandemic: A review and an update on cases in Africa, Asian Pacific Journal of Tropical Medicine, 13(5):199203.

(2) Al Awadhi, A. M., Al-Saifi, K., Al-Awadhi, A., \& Alhamadi, S. (2020). Death and contagious infectious diseases: Impact of the COVID-19 virus on stock market returns, Journal of Behavioral and Experimental Finance, 100326.

(3) Alber, N. (2020). The Effect of Coronavirus Spread on Stock Markets: The Case of the Worst 6 Countries. Available at SSRN 3578080.

(4) Antonis, A., Katrakilidis, C., \& Tsaliki, P. (2013). Wagner's Law versus Keynesian Hypothesis: Evidence from pre-WWII Greece, Panoeconomicus, 60(4): 457-472.

(5) Badar Nadeem, A. (2020). Stock market reaction to COVID-19: Cases or fatalities, Reasecrh of International Business and Finance, 54, 101249.

(6) Ben Ayed, W., Medini, F., \& Lamouchi Ammar, R. (2020). Stock Market under the Global Pandemic of COVID-19: Evidence from Tunisia. Available at SSRN: https://ssrn.com/abstract=3598726 or http://dx.doi.org/10.2139/ssrn.3598726.

(7) Brüssow, H. (2020). The Novel Coronavirus-A Snapshot of Current Knowledge, Microbial Biotechnology. https://doi.org/10.1111/1751-7915.13557.

(8) El-Basuon, H. 2020. Effect of COVID-19 on the Arab Financial Markets Evidence from Egypt and KSA, IOSR Journal of Business and Management, 22(6): 14-21.

(9) Elsayed, A. \& Elrhim, M. A. (2020). The Effect Of COVID-19 Spread On Egyptian Stock Market Sectors. Available at SSRN: https://ssrn.com/abstract=3608734 or http://dx.doi.org/10.2139/ssrn.3608734.

(10) Engle, Robert F., \& Clive W. J. Granger. (1987). Co-Integration and Error Correction: Representation, Estimation, and Testing, Econometrica, 55(2): 251-276.

(11) Evans, O. (2020). Socio-economic impacts of novel coronavirus: The policy solutions, BizEcons Quarterly, 7, 312.

(12)Fauci, A. S., Lane, H. C., \& Redfield, R. R. (2020). Covid-19-Navigating the Uncharted. The New England Journal of Medicine, 10,1056/NEJMe2002387.

(13) Gentile, I., \& Abenavoli, L. (2020). COVID-19: Perspectives on the Potential Novel Global Threat, Reviews on Recent Clinical Trials, 15(2), 1. 
(14) Goodell, J. W. 2020. COVID-19 and finance: Agendas for future research, Finance Research Letters. Available at: https://doi.org/10.1016/j.frl.2020.101512.

(15) Gormsen, N. J., \& Koijen, R. S. J. (2020). Coronavirus: Impact on Stock Prices and Growth Expectations, Working Paper, University of Chicago Booth School of Business.

(16) HaiYue, L., Aqsa. M., CangYu, W., Lei Z., \& Zaira, M. (2020). The Covid-19 outbreak and Affected Countries Stock Markets response, International Journal of Environmental Research and Public Health, 17, 2800.

(17) Harris, R. I. D., \& Sollis, R. (2003). Applied time series modelling and forecasting, Chichester, West Sussex, England, J. Wiley.

(18) Johansen, S., \& Katarina, J. (1990). Maximum Likelihood Estimation and Inference on Cointegration - With Applications to Demand for Money, Oxford Bulletin of Economics and Statistics, 52(2): 169-210.

(19) Morley, B. (2006). Causality between Economic Growth and Immigration: An ARDL Bounds Testing Approach, Economics Letters, 90(1): 72-76.

(20) Narayan Paresh, K. 2005. The Saving and Investment Nexus for China: Evidence From Cointegration Tests, Applied Economics, 37(17):1979-19.

(21) Pesaran, Mohammad, H., \& Yongcheol, S. (1999). An Autoregressive Distributed Lag Modeling Approach to Cointegration Analysis, In Econometrics and Economic Theory in the 20th Century: The Ragnar Frisch Centennial Symposium, ed. Steinar Strøm, 371-413, Cambridge: Cambridge University Press.

(22) Pesaran, Mohammad H., Yongcheol Shin, \& Richard J. S. (2001). Bounds Testing Approaches to the Analysis of Level Relationships, Journal of Applied Econometrics, 16(3): 289-326.

(23) Qing, H., Junyi, L., Sizhu W., \& Jishuang, Y. (2020). The impact of Covid-19 on stock markets, Economic and political studies.

(24) Qiu. W. R., Mao. A. S., \& Chu, C. (2017). The Pandemic and its Impacts, Health, Culture and Society, 9(10).3-11.

(25) Sansa, N. A. (2020). The Impact of the COVID-19 on the Financial Markets: Evidence from China and USA, Electronic Research Journal of Social Sciences and Humanities, 2.

(26) Senay. A., \& Merter, M. (2020). The Endogeneity of the Natural Rate of Growth: An Application to Turkey, Panoeconomicus, 57(4):447-469.

(27) Shang, W., Yang, Y., Rao, Y., \& Rao, X. (2020). The outbreak of SARS-CoV-2 pneumonia calls for viral vaccines, npj Vaccines, 5(1), 1-3.

(28)Zhang, D., Hu, M., \& Ji, Q. 2020. Financial markets under the global pandemic of COVID19, Finance Research Letters, 101528. 